\title{
Conservação da agrobiodiversidade e soberania alimentar em assentamento rural no Pantanal de Cáceres, Mato Grosso
}

A agricultura familiar tem conseguido manter em pequenos espaços uma produção agrícola diversificada visando o autoconsumo, soberania alimentar, obtenção de renda e conservação da agrobiodiversidade. O objetivo deste estudo foi apresentar como é desenvolvida a produção agrícola no Assentamento Laranjeira I, situado na borda do Pantanal de Cáceres - MT, bem como relacioná-la com a conservação da agrobiodiversidade e manutenção da soberania familiar local. À coleta de dados adotou-se abordagem qualitativa: questionário estruturado e métodos antropológicos. A amostra reuniu 43 lotes próximos às nascentes de água. Para a análise dos dados socioeconômicos e da produção agrícola utilizou-se abordagem quantitativa (FR\%). Dos lotes visitados $51 \%$ utilizam a agricultura principalmente para o autoconsumo de suas famílias em espaços como quintal e roça. Alguns cultivam apenas no quintal por ser um espaço de fácil acesso próximo ao domicílio e organizado pelas mulheres e filhos, por redução de perdas por roubos e/ou adversidades meteorológicas. Os moradores cultivam principalmente variedades de verduras, leguminosas e tubérculos tornando o sistema de produção estável e diversificado. Apenas $17 \%$ utilizam sistema com apenas uma cultura. Em $32 \%$ dos lotes foram identificadas a utilização de práticas tradicionais agrícolas como orientação da lua no cultivo e formação de roças coletivas, com a repartição de alimentos produzidos para consumo das famílias e comercialização do excedente. Constatou-se a presença da produção por experimentação por um morador. Esta população possui forte identidade cultural com a vida camponesa, e mesmo que as condições de produção comercial não tenham sido favoráveis não abandona o lote visto como fruto de suas lutas em movimentos sociais. A terra representa a história de vida desses moradores, garantindo a manutenção da soberania alimentar das famílias assentadas bem como a conservação da agrobiodiversidade.

\section{Agrobiodiversity conservation and food sovereignty in rural settlement in the Pantanal area of Caceres, Mato Grosso}

\begin{abstract}
Family farming has managed to keep, in small spaces, a diversified agricultural production aiming self-consumption, food sovereignty, income obtainment and agro biodiversity conservation. This study's goal was to present how the agricultural production is developed in the settlement Laranjeira I, located in the Pantanal edge of Cáceres - MT, and also relate the production with the agro biodiversity conservation and the maintenance of local family sovereignty. For data collection, the qualitative approach was adopted: structured questionnaire and anthropological methods. The sample assembled 43 sites near the water springs. Quantitative approach (FR\%) was used for the socioeconomic data and agricultural production analysis. Fifty-one percent of the visited sites uses agriculture mainly for their families' self-consumption in areas such as yards and slashes. Some only grow in the yard because it is an easily accessible space next their homes since it is maintained by women and children, and to reduce losses by theft and/or weather adversities. Local people mainly grow varieties of vegetables, legumes and tubers, making it a steady and diversified production system. Only seventeen percent uses monoculture system. In thirty-two percent of the sites, traditional agricultural practices were identified, like moon orientation in cultivation and collective slashes formation, with food sharing for the families' consumption and sale of the surplus. The presence of production by experimentation by one of the residents was found. This population has a strong cultural identity related to peasant life, and even if the commercial production conditions have not been favorable, they do not abandon the site since it is considered the product of their struggles in social movements. The land represents the story of life of its residents, ensuring the maintenance of food sovereignty of the settled families and agro biodiversity conservation.

Keywords: Agricultural Practices; Agrarian Reform Settlement; MST; Family Farming.
\end{abstract}

Topic: Química Agrícola e Ambiental

Reviewed anonymously in the process of blind peer.

Thaís Martins dos Santos

Universidade do Estado de Mato Grosso, Brasil

http://lattes.cnpq.br/6131255724140711

thaisms.enf@gmail.com

Porfírio dos Santos Júnior

Universidade do Estado de Mato Grosso, Brasil

http://lattes.cnpq.br/6845203941633819

porfiriojuniorbio@gmail.com

Solange Kimie Ikeda Castrillon

Universidade do Estado de Mato Grosso, Brasil

http://lattes.cnpq.br/3373034135331436

solangeikeda@gmail.com
Received: $18 / 04 / 2016$

Approved: 20/05/2016

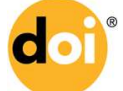

DOI: 10.6008/SPC2179-6858.2017.001.0007
Referencing this:

SANTOS, T. M.; SANTOS JÚNIOR, P.; CASTRILLON, S. K. I.; CARNIELLO, M. A.. Conservação da agrobiodiversidade e soberania alimentar em assentamento rural no Pantanal de Cáceres, Mato Grosso. Revista Ibero-Americana de Ciências Ambientais, v.8, n.1, p.74-90, 2017. DOI: http://doi.org/10.6008/SPC2179-6858.2017.001.0007 


\section{INTRODUÇÃO}

Os assentamentos de reforma agrária são conhecidos pela luta em movimentos sociais daqueles que reivindicam o direito ao acesso da posse de terras, e que não a possuem, mas tem vocação ou origem campesina. Ao analisarmos a atuação da Via Campesina no Brasil, pode-se afirmar que o MST (Movimento Sem-Terra) é o movimento social mais consolidado nacionalmente por levantar a "bandeira" da autonomia (CAMPOS, 2006). Estes assentamentos possuem como finalidade dispor de um imóvel rural para uma família que não possui condições econômicas de obtê-lo por outras vias, e ainda, dar condições de moradia e de produção familiar que garantam a segurança alimentar para uma população que até então se encontrava sob risco alimentar e social (BRASIL, 2014).

Neste contexto, tem-se que a Via Campesina (uma articulação internacional das organizações do campo) tem como características essenciais para a continuidade do modo de vida camponês: a reforma agrária e soberania alimentar (CAMPOS, 2006). A reforma agrária não deve ser compreendida pelos camponeses somente como um processo de distribuição da posse de terra, e sim de que o acesso à terra é a garantia de valorização de sua cultura, da autonomia das comunidades e de uma nova visão de preservação dos recursos naturais, para a humanidade e para as gerações futuras (VIA CAMPESINA DO BRASIL, 2002).

A produção agrícola desenvolvida em assentamentos rurais de reforma agrária tem grande importância para as famílias assentadas, principalmente no que se refere a garantia e acesso a alimentos de qualidade. Rosset (2004), afirma que o conceito de soberania alimentar é mais adequado do que segurança alimentar quando tratamos de reforma agrária, isto porque o conceito de segurança alimentar não relaciona a procedência do alimento ou como é produzido, apenas diz sobre o acesso à quantidade suficiente. Em contrapartida, a soberania alimentar está ancorada na proteção das agriculturas locais com vistas à concepção de políticas agrárias, agrícolas e alimentares (MARQUES, 2010).

Define-se como soberania alimentar, segundo Wittman et al. (2010), como um direito dos camponeses de controlarem os próprios sistemas alimentares, modos de produção, mercados, acesso ao crédito, culturas alimentares e o meio ambiente, isto tudo como uma alternativa para contrapor o modelo neoliberal dominante de agricultura: o agronegócio. De acordo com Altiere (2008) o agronegócio, além de não se mostrar eficiente para atender as demandas em alimento da humanidade, asfixia os "serviços ecológicos" dos quais a população humana é dependente. O padrão tecnológico fundado no uso intensivo de insumos químicos, sementes melhoradas e híbridas e maquinaria pesada, exige forte consumo de energia, mostra-se extremamente dispendioso e não se ajusta às condições da pequena agricultura familiar, conforme previsto na lei no 11.326/2006 que dispõe sobre a agricultura familiar (MALUF et al., 2000).

Diante dessa problemática é que a soberania alimentar torna-se essencial, pois enfatiza os circuitos locais de produção-consumo e ações organizadas para obter acesso à terra, água ou agrobiodiversidade para produzir alimentos com métodos agroecológicos. A multifuncionalidade da agricultura familiar com base nesse sistema de produção só é visível quando as paisagens estão dominadas pelas pequenas produções 
agrícolas biodiversificadas das comunidades rurais, caracterizadas como mais produtivas, de economia mais saudável e menores problemas sociais do que as grandes produções monoculturas (MARQUES, 2010).

A agricultura familiar deve ser vista como prioridade na agenda do governo e não negligenciada com baixos investimentos e dificultando o acesso ao crédito e assistência, tendo em vista que são estas unidades produtivas que contribuem fortemente para manutenção da soberania alimentar das famílias assentadas e da população local. Porto-Gonçalves (2005) afirma que o grande número de pessoas que encontram acesso à terra nos assentamentos de reforma agrária vem contribuindo para não engordar as dramáticas cifras de desemprego nas cidades.

No Estado de Mato Grosso o espaço destinado à pequena propriedade ainda é ínfimo, se não irrisório. Fica evidente que para os migrantes ou mesmo residentes que demandam terra para sua reprodução social ficaria destinada apenas uma pequena parcela de terras pouco produtivas ou muito remotas e inóspitas. Terras que precisam de muitos investimentos para produzir, portanto, pouco adequadas para a produção agrícola de famílias sem recursos. Esse tipo de agricultura familiar está baseado nos recursos naturais que um solo pode oferecer, uma vez que o poder de investimento é muito baixo (CUNHA et al., 2002). Esta é a situação do Assentamento Laranjeira I, localizado na região sudoeste do Estado de Mato Grosso e objeto de estudo deste trabalho, que está situado na borda do Pantanal, e em decorrência de sua localização geográfica existe a necessidade de planejar atividades produtivas adequadas ao ordenamento territorial com enfoque socioeconômico e cultural para esta área (KREITLOW et al., 2013).

No assentamento Laranjeira I, bem como na maioria dos assentamentos brasileiros, existem limitações e dificuldades para a pequena produção agrícola que incluem desde a falta de assistência técnica especializada até a falta de recursos ecossistêmicos tais como a água que dificulta e inviabiliza a produção nas pequenas propriedades. Mesmo diante das dificuldades encontradas os assentados mantem em suas propriedades a prática da produção agrícola, por meio da agricultura familiar definida aqui como a unidade de produção que liga intimamente a propriedade e o trabalho à família (SAVOLDI et al., 2010).

Estudos realizados em Mato Grosso têm revelado que pequenos agricultores tradicionais e familiares têm conseguido manter, uma alta agrobiodiversidade em pequenos espaços, de até poucos hectares, tal como as roças e os quintais, desenvolvendo para isso diversas estratégias de grande importância como o modo o qual o agricultor maneja estes espaços e como os articula, tanto no âmbito da propriedade, como nas esferas mais amplas, de comunidade e região, promovendo a circulação de propágulos e informação, por meio das redes sociais (AMOROZO, 2013).

Em uma abordagem ecológica e genética, os quintais podem representar um espaço de resistência às monoculturas (AMOROZO, 2008), pois, ao contrário de cultivos monoespecíficos, proporcionam a manutenção de uma alta diversidade inter e intraespecífica, resultantes de experimentação e seleção local, assim como de trocas e circulação de espécies levadas de um ambiente para outro (WILLIAMS, 1997). Além de serem fonte para o autoconsumo, soberania alimentar e recursos financeiros, são também um repositório e um lugar para experimentação de espécies incomuns e de variedades de plantas (PADOCH et al., 1990; KUMAR et al., 2004). 
Diante do contexto apresentado, este estudo teve como objetivo analisar o sistema de produção agrícola das pequenas propriedades do Assentamento Laranjeira I, de forma a apresentar como as famílias assentadas organizam suas unidades produtivas, bem como as formas de manejo utilizadas e as dificuldades encontradas na produção agrícola.

\section{METODOLOGIA}

\section{Área de estudo}

Este estudo foi realizado no Assentamento Rural Laranjeira I, pertencente ao município de Cáceres, Mato Grosso. Está localizado a $80 \mathrm{~km}$ de distância da sede do município, sob as coordenadas geográficas $57^{\circ} 33^{\prime \prime} 41,83^{\prime}$ Oeste e $16^{\circ} 34^{\prime} 04,10^{\prime \prime}$ Sul. Este é um assentamento instituído pelo Instituto Nacional de Colonização e Reforma Agrária (INCRA), com data de criação em 24 de fevereiro de 1997, com área total de 10.944 hectares, cada lote de 22 a 28 hectares e 125 famílias assentadas (BRASIL, 2014b).

A área possui características fitofisionômicas de Cerrado estabelecido sobre afloramento rochoso com formação serrana (Formação Serra das Araras) e interligada a planície alagada do Pantanal matogrossense (CASTRILLON et al., 2012). A cerca de $7 \mathrm{Km}$ da sede do assentamento, em linha reta, está localizada a Baía Grande do Pantanal, denominada pela população do assentamento de "Lagoa do Pantanal", que possui conecção direta com o Pantanal do município de Poconé (KREITLOW et al., 2013). No território do assentamento afloram diversas nascentes e cursos d'água importantes que deságuam no Pantanal. São fundamentais para garantir o abastecimento hídrico e qualidade de vida dos moradores locais (Figura 1).

Atualmente, o número de famílias abrigadas é superior à capacidade que o INCRA estabeleceu na sua fundação, de 45 famílias (BRASIL, 2014a). Este número elevado de famílias além da capacidade, pode estar associado à preferência dos assentados em manter residência fixa em região com maior disponibilidade de recursos hídricos, visto que neste assentamento afloram quatro nascentes de água e formam-se córregos extensos, o que o diferencia dos demais assentamentos rurais estabelecidos nesta mesma região. Além deste fator, pode-se inferir as famílias grandes que se mantiveram acampadas em busca da obtenção da terra permaneceram juntas assentando-se no mesmo projeto de assentamento.

Os moradores que estão no assentamento desde momentos anteriores a sua fundação revelaram que a luta pela conquista da terra foi árdua. A posse do lote por alguns tem sua história marcada pela permanência em Acampamentos do Movimento Sem Terra (MST) situados no município de Cáceres, sendo eles o "Margarida Alves" (distrito Caramujo) e o Facão. Relatam que permaneceram por dois anos "debaixo de lona" (modo pelo qual se referem ao período em que ficaram acampados). Este período é dividido entre o tempo em que permaneceram nos acampamentos (cerca de 1 ano e seis meses), até a ida para a fazenda em que seriam criados os projetos de assentamentos rurais, ainda sem a distribuição dos lotes.

Os moradores afirmaram que a permanência em barracos por mais seis meses na área denominada por eles como "Fazendinha" foi uma forma encontrada de pressionar o INCRA à liberar mais rapidamente as terras. Este histórico de luta pela posse da terra no assentamento Laranjeira I, corrobora o descrito por 
Tsukamoto e Asari (2003), no qual os autores afirmam que o processo de assentamento se dá por etapas, e até a conquista da terra há que se passar pela fase de acampamento, em que ocupa-se as terras improdutivas como forma de pressionar as autoridades competentes (INCRA) na agilização da negociação, demarcação e distribuição dos lotes.
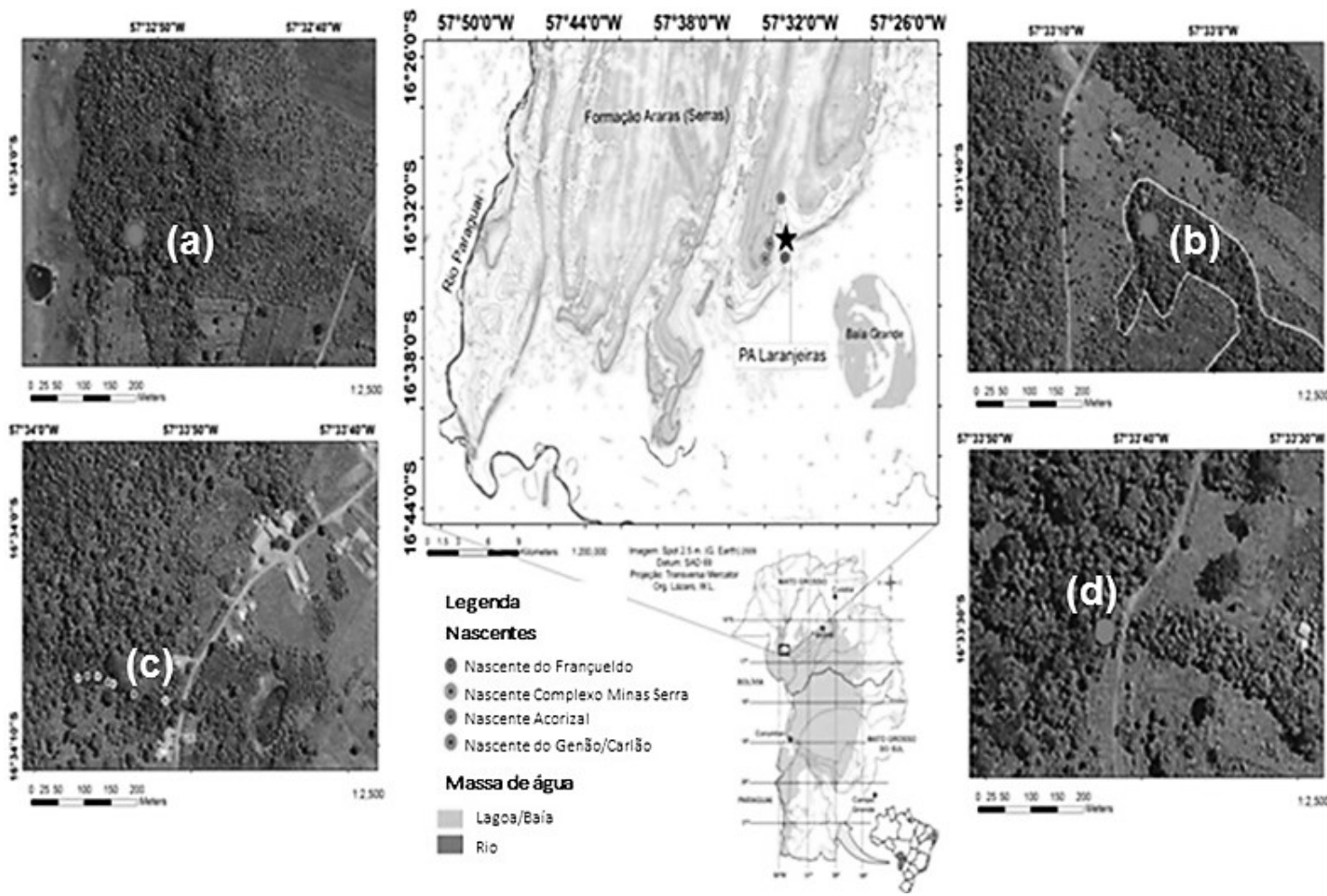

Figura 1: Localização do Assentamento Laranjeira I e das nascentes de água, 2013-2014. Legenda: (a). Nascente do Françueldo. (b): Nascente Acorizal. (c): Nascente Complexo Minas Serra. (d): Nascente do Genão/Carlão. Fonte: CASTRILLON et al. (2012).

Este período foi marcado por luta intensa e idas até Brasília por grupos que lideravam o movimento, atualmente assentados no assentamento na área requerida. Esta persistência, a característica militante e o anseio pelo mesmo objetivo das pessoas envolvidas no MST, são fatores que tornam este movimento de reforma agrária mais importante do país para a conquista da terra. Segundo Buth e Corrêa (2006), o acesso à terra pelos assentados rurais, indica a reterritorialização do espaço, de modo a reproduzir e recriar neste espaço o estabelecimento de novos elementos, perspectivas e mudanças das relações sociais por meio do rearranjo no processo produtivo, diversificação da produção e introdução novas atividades no meio rural. As mesmas autoras afirmam ainda, sob esta perspectiva, que "o território pode ser entendido como resultado de um processo histórico da construção do espaço por agentes sociais que lhe imprimem suas características socioculturais".

\section{Procedimentos metodológicos de coleta e análise dos dados}

Este estudo é resultado de uma dissertação de mestrado do Programa de Pós-Graduação em Ciências Ambientais da Universidade do Estado de Mato Grosso, constituída de uma meta derivada do Projeto “Recuperação das nascentes e fragmentos de mata ciliar do córrego do Assentamento Laranjeira I e 
mobilização para conservação dos recursos hídricos no Pantanal Matogrossense", conhecido por Projeto Laranjeiras.

É importante destacar que neste artigo não se teve a pretensão de estudar como as formas de cultivo dos sistemas agrícolas estudados ajudam ou não a recuperar os fragmentos de mata ciliar, e sim apenas analisar como está configurado sistema de produção agrícola local.

Para a realização da pesquisa foi adotada a abordagem qualitativa, conforme proposição de Ludke et al. (1986). Foram utilizadas como ferramentas de coleta de dados um levantamento socioeconômico, cultural e relacionados às práticas agrícolas dos sujeitos envolvidos na pesquisa a partir de formulário estruturado.

Também foram adotados técnicas e métodos antropológicos, tais como, a "observação participante" e "diário de campo", em conformidade com o proposto por autores como Bernard (1988), Martin (1995), Alexíades (1996), Geertz (2000), Viertler (2002), Albuquerque et al. (2004).

Foram selecionadas 43 propriedades (lotes) para compor a amostra desta pesquisa, o que corresponde a $34 \%$ do total de domicílios do assentamento que somam até o presente momento em 125 lotes. Foi adotado como critério de inclusão os lotes estabelecidos próximos às regiões de nascentes e cursos d'água, e ainda aqueles localizados na região mais próxima à Baía Grande do Pantanal, denominada pelos moradores do assentamento por "Sete Lotes".

A coleta de dados foi iniciada somente após a aprovação do projeto pelo Comitê de Ética em Pesquisa (CEP) sob o Parecer no 400.799 em 12 de setembro de 2013, e mediante a assinatura do Termo de Compromisso das Instituições Envolvidas no estudo e do Termo de Consentimento Livre e Esclarecido (TCLE) daqueles que concordaram em participar, conforme determinação da Resolução CNS (Conselho Nacional de Saúde) 466 de 12 de dezembro de 2012 do Ministério da Saúde.

Os dados foram coletados no período de setembro de 2013 a setembro de 2014, com a realização de observação das atividades cotidianas da população local ao longo de um ano. Para tanto, foram realizadas inicialmente visitas semanais frequentes e, posteriormente, visitas mensais com permanência durante finais de semana para o acompanhamento das atividades diárias dos envolvidos na pesquisa.

A organização dos dados foi realizada em planilhas por meio da categorização dos mesmos, seguida pela análise por meio de estatística descritiva (Frequência Relativa (FR\%) e Frequência Absoluta (FA), utilizando-se o Excel 2013. Para a confecção do mapa da área de estudo foi realizado o georreferenciamento em campo utilizando o GPS Garmim - Datum WGS 84. O mapa foi confeccionado por meio do programa ArcGis.

\section{RESULTADOS E DISCUSSÃO}

\section{Breve caracterização geral da população estudada}

A população do Assentamento Laranjeira I é formada por matogrossenses e migrantes de diferentes regiões brasileiras. Dos 43 moradores entrevistados, 76\% são migrantes de outros Estados, 22\% são de Mato Grosso e 2\% do Paraguai. Destaca-se a presença de migrantes da região Nordeste (33\%) e Sudeste (32\%) do 
Brasil. Esta é uma característica dos assentamentos rurais, compostos em sua maioria por populações migrantes de diferentes origens e culturas.

Amorozo (2013) afirma que os assentamentos rurais são espaços nos quais estão inseridos agricultores de procedências e experiências de vida diferentes. Esta afirmação revela a miscigenação cultural e de formas divergentes de manejo das práticas agrícolas e ambientais em uma só região.

Do total dos sujeitos envolvidos na pesquisa $53,5 \%$ são do sexo feminino e $46,4 \%$ do masculino. A média de idade é de 51 anos, sendo as faixas etárias de maior destaque de 36 a 45 anos (21\%) e 66 a 75 anos (21\%), e a de menor percentual dos 16 aos 25 anos (7\%). Do tempo de residência no assentamento, 51\% residem há 16 e 18 anos, e 16\% são moradores novos (até 5 anos). Dos 43 moradores entrevistados, 63\% são assentados pelo INCRA e $37 \%$ compraram as propriedades de antigos assentados.

Esta população possui forte vínculo com a terra e o ambiente natural que os envolve, e na maioria das propriedades evidenciou-se que a terra é vista como fonte de produção para o autoconsumo e, parcialmente, como fonte de renda. No entanto, a pecuária de gado leiteiro é a principal fonte de obtenção de renda, uma característica das populações que vivem na região do Pantanal matogrossense.

\section{Panorama da produção agrícola no Assentamento Laranjeira I}

Dentre as fontes de sustento, a agropecuária destaca-se como a principal delas, sendo a pecuária responsável por maior obtenção de renda em $67 \%$ das propriedades. A pecuária de gado de corte é desenvolvida em $50 \%$ dos lotes, pecuária leiteira em $27 \%$ e a agricultura em $51 \%$.

Silva et al. (2012) realizaram um estudo nos assentamentos rurais do município de Cáceres e identificaram que em média 70\% das áreas dos assentamentos estão ocupadas com pastagens e apenas 30\% com atividades agrícolas. Segundo os mesmos autores, a produção agrícola nos assentamentos estudados apresenta quadros mais ou menos semelhantes em termos de exploração de cultura temporária, como a mandioca, o milho, o feijão, o arroz e as hortaliças, sendo que o cultivo desses produtos é, na maioria das vezes, destinado ao consumo familiar e a alimentação das criações, dado também constatado no assentamento Laranjeira I em que os moradores cultivam principalmente plantas perenes em seus pequenos espaços destinados à produção agrícola.

A atividade agrícola praticada pelos moradores deste assentamento está principalmente voltada para o autoconsumo, no entanto, cerca de $25 \%$ das propriedades comercializam o excedente da produção. Quando há "fartura" da produção agrícola, como os moradores denominam a sobra da produção, alguns produtores comercializam dentro do assentamento, ou dividem com os familiares e/ou amigos, mas são poucos os que fazem o escoamento da produção para a cidade com finalidade comercial em maior escala. Até a data de realização deste estudo não haviam moradores que entregavam sua produção agrícola para o Programa de aquisição de alimentos (PAA). Uma moradora mencionou que entregava alguns dos seus produtos agrícolas (principalmente frutas e hortaliças) para a escola do assentamento pelo Programa Nacional de Alimentação na Escola (PNAE), e que deixou de entregar porque sua produção passou a ser 
insuficiente à demanda da escola. A mesma disse, que esta era uma renda extra que ajudava nas despesas da família.

$\mathrm{O}$ ato de "compartilhar ou doar" o excedente da produção agrícola também foi constatado por Menasche et al. (2008) no estudo com 48 famílias rurais na região do Vale do Taquari no Rio Grande do Sul no período de 2004 a 2006. Os autores afirmam que o ato de doação dos alimentos sem interesse pode ser considerado uma dádiva paradoxal, uma vez que existe a gratuidade como ato incondicional capaz de selar a aliança que beneficia a todos os envolvidos no processo, na qual as trocas garantem que haja maior diversificação dos alimentos disponíveis, fato que assegura o acesso aos alimentos, um dos pilares da soberania alimentar. No entanto, existe o comércio entre as propriedades vizinhas o que amplia possibilidades de ingresso de renda e, localmente, a circulação de riqueza, o que pode ser evidenciado como aspecto que comprometa o acesso aos alimentos.

Diante da formação de importantes redes sociais, o meio rural pode ser compreendido como um espaço suporte de relações sociais específicas, que se constroem, se reproduzem ou se redefinem sobre este mesmo espaço, e para a sua compreensão é preciso considerar sua dinâmica social interna, isto é, aquela que resulta da maior ou menor intensidade e complexidade da vida local (WANDERLEY, 2000).

Os moradores que desenvolvem a atividade agrícola (51\%) afirmam que os fatores que dificultam a produção no assentamento Laranjeira I são as condições climáticas da região. Os mesmos relacionam a limitação para a produção agrícola principalmente a improdutividade da terra (afloramentos rochosos) e a seca que acomete a região, que embora seja conhecida por suas importantes nascentes de água que deságuam na Baía do Pantanal, o uso desenfreado e insustentável deste recurso pela população local tem tornado o acesso a água um problema constante no assentamento estudado.

Há ocorrência de alagamento das propriedades, nas porções de áreas úmidas, que permanecem alagadas grande parte do ano, devido à proximidade com a Lagoa do Pantanal. Esse fator restringe o uso da terra para atividades agrícolas, e consequentemente tem maior destaque como atividade produtiva a pecuária. Estes dados também foram mapeados por Kreitlow et al. (2013) na mesma região deste estudo.

Isto nos faz refletir sobre a heterogeneidade presente nesse local, quando se trata da interferência das condições climáticas e sazonais para a atividade de produção agrícola. Enquanto uns moradores não conseguem produzir pelo excesso de água (alagamentos) outros encontram dificuldades e limitações para a produção pela falta de água.

Um dos problemas mais mencionados pelos moradores para a manutenção da atividade agrícola principalmente nas roças de cultura de milho, feijão e mandioca, é o ataque de animais silvestres tais como porco do mato, queixada e pássaros. Os moradores que sofrem com esses ataques afirmam que não "compensa" plantar e não conseguir colher nem ao menos a metade da produção agrícola. Isto em parte, se deve a localização geográfica em que os lotes foram implantados na formação serrana e aqueles conectados às áreas úmidas do Pantanal (próximos a Lagoa do Pantanal).

O ano de 2014 foi um ano atípico para a população do assentamento, isto porque, em 2013 ocorreu uma das maiores secas e no ano seguinte (2014) houve aumento expressivo do índice de chuvas na região. 
O aumento da frequência de chuvas na região, de certa forma poderia ser um fator que contribuiria para a formação de roças nas regiões mais secas do assentamento. No entanto, as enxurradas formadas durante o período das chuvas, fizeram com que algumas propriedades tivessem suas produções agrícolas totalmente destruídas.

Os moradores locais afirmam ainda, que as péssimas condições da estrada que dá o acesso do assentamento à sede do município dificultam o escoamento da produção para a venda na cidade, e por isso, a maioria deles não produz em grandes quantidades para fins de comercialização produzindo apenas para o autoconsumo.

Conforme Cunha et al. (2002), a maioria dos assentamentos estão situados em terras desgastadas, de má qualidade para fins agrícolas, consideradas áreas improdutivas, sem a mínima infraestrutura, ou lotes em áreas de mata fechada com péssima acessibilidade, além dos constrangimentos das leis ambientais, são realidades com que convivem os migrantes que ainda hoje optam pela vida no campo em especial no Estado de Mato Grosso.

Mesmo diante dos fatores que contribuem para o insucesso da atividade agrícola no assentamento Laranjeira I, constatou-se que um pouco mais da metade (51\%) dos moradores entrevistados ainda mantem a prática agrícola e destinam como espaços de cultivo o quintal e as roças, não tão somente tendo a produção como finalidade de autoconsumo das famílias, mas também como forma de manter e expressar sua identidade campesina evitando a degradação do saber-fazer agrícola dessa gente que vive da terra e do que ela oferece.

\section{O quintal como unidade produtiva a serviço da soberania alimentar e conservação da agrobiodiversidade}

Conforme Pedroga et al. (2008), considera-se que nas sociedades atuais o quintal, seja ele urbano ou rural, é o espaço mais próximo em que essas populações plantam, manejam, criam animais, desenvolvem atividades de lazer, religiosas e de trabalho cotidiano. Brito et al. (2000) afirmam que o quintal é uma porção de terra próximo à residência, de acesso fácil e cômodo, na qual se cultivam ou se mantêm múltiplas espécies que fornecem parte das necessidades nutricionais da família, bem como outros produtos, como lenha e plantas medicinais.

O exposto pelos autores supracitados, elucida o encontrado no assentamento estudado. O quintal das propriedades amostradas é uma unidade organizada de modo a abrigar outras unidades de espaços menores destinadas ao cultivo de horta, plantas medicinais e alimentares, à criação de animais, ao lazer e festa, ao armazenamento da produção agrícola e à ornamentação da residência. Por esta alta funcionalidade e inúmeras possibilidades de uso o quintal representa grande importância para as famílias deste assentamento.

Neste aspecto, foi registrada em $98 \%$ das propriedades a importância deste espaço principalmente para o cultivo de alimentos para o autoconsumo. As plantas alimentares, além de serem cultivadas na roça, também são produzidas no espaço mais próximo da casa para facilitar as atividades cotidianas de manejo e coleta rápida para o uso. Constatou-se também, que nas propriedades onde não ocorre a prática de formação 
de lavouras, os moradores trazem a "roça para dentro" do quintal cultivando espécies alimentares exclusivamente neste espaço. Isto revela o quintal como importante unidade produtiva de alimentos de origem vegetal e animal destinados ao autoconsumo, e ainda a manutenção de espécies de interesse para os moradores neste espaço.

O hábito de cultivar espécies agrícolas no quintal enfatiza as práticas de conservação da diversidade agrícola, tais como coleta, caracterização e adaptação de germoplasma das variedades locais (ALMEIDA et al., 2002), e ainda caracteriza a importância do quintal no manejo e conservação da biodiversidade (BRITO et al., 2000).

Dentre as variedades agrícolas mais cultivadas nos quintais e que contribuem para a segurança alimentar das famílias estão a batata doce (Ipomoea batatas (L.) Lam.), cenoura (Daucus carota L.), tomate (Solanum lycopersicum L.), alface (Lactuca sativa L.), couve (Brassica oleracea L.), rúcula (Eruca vesicaria (L.) Cav.), inhame (Colocasia esculenta (L.) Schott), mandioca (Manihot esculenta Crantz), banana (Musa paradisiaca L.), pimenta (Capsicum annuum L.; Capsicum chinense Jacq.; Capsicum baccatum L.), quiabo (Abelmoschus esculentus (L.) Moench), abóbora (Cucurbita pepo L.), melancia (Citrullus lanatus (Thunb.) Matsum. \& Nakainb), milho (Zea mays L.), feijão (Phaseolus vulgaris L.), abacaxi (Ananas comosus (L.) Merr.), manga (Mangifera indica L.), laranja (Citrus aurantium L.), café (Coffea arabica L.) entre outras.

Deste modo, os quintais do assentamento Laranjeira I atuam como sistemas intensivos "estáveis", pois abrigam espécies perenes, destacando-se o papel que possuem como espaços de promoção de diversificação, além de que o agricultor pode manter neste espaço, intencionalmente, espécies e variedades cultivadas, ao lado de espécies nativas aparentadas às culturas, introduzidas deliberadamente por ele, com o fim de renovar o vigor do germoplasma (AMOROZO, 2013).

No assentamento Laranjeira I é comum a formação de hortas nos quintais, principalmente no período da estiagem, sendo que este espaço é implantado e manejado na maioria das propriedades pelas mulheres e filhos. Amorozo (2013) afirma que os quintais, assim como em qualquer sistema agrícola, são espaços multifuncionais onde se pratica cultivo contínuo, tanto de plantas de ciclo curto, quanto de ciclo longo. A autora afirma ainda que a proximidade com o domicílio permite aproveitar a mão-de-obra feminina no intervalo das tarefas domésticas, bem como a contribuição de velhos e crianças, o que facilita o cultivo de grande variedade de espécies, além de ser mais fácil o controle sobre perdas da produção devido a roubo.

Desta forma, assim como no trabalho de Menasche et al. (2008) este estudo mostrou que são as mulheres, muitas vezes com a participação das filhas e de filhos mais jovens, as principais responsáveis pela horta e pelos pequenos cultivos e criações voltados ao autoconsumo, assim como pelos serviços domésticos, aí incluso o preparo das refeições, ocorrendo a divisão de trabalho dentro das unidades familiares, em que o homem é o responsável na maioria das vezes pela lida na roça e outras atividades geradoras de renda.

A figura 2 elucida a organização dos quintais de duas propriedades amostradas por meio da utilização de croquis. Nas duas propriedades constatou-se o hábito de formação de hortas próximas às residências e ainda que estes espaços são de responsabilidade das mulheres, ambas não têm poço artesiano, isto porque 
utilizam a água vinda do córrego por força gravitacional, criação de animais de pequeno porte (galinhas e porcos) no quintal e cultivo de plantas frutíferas de interesse.

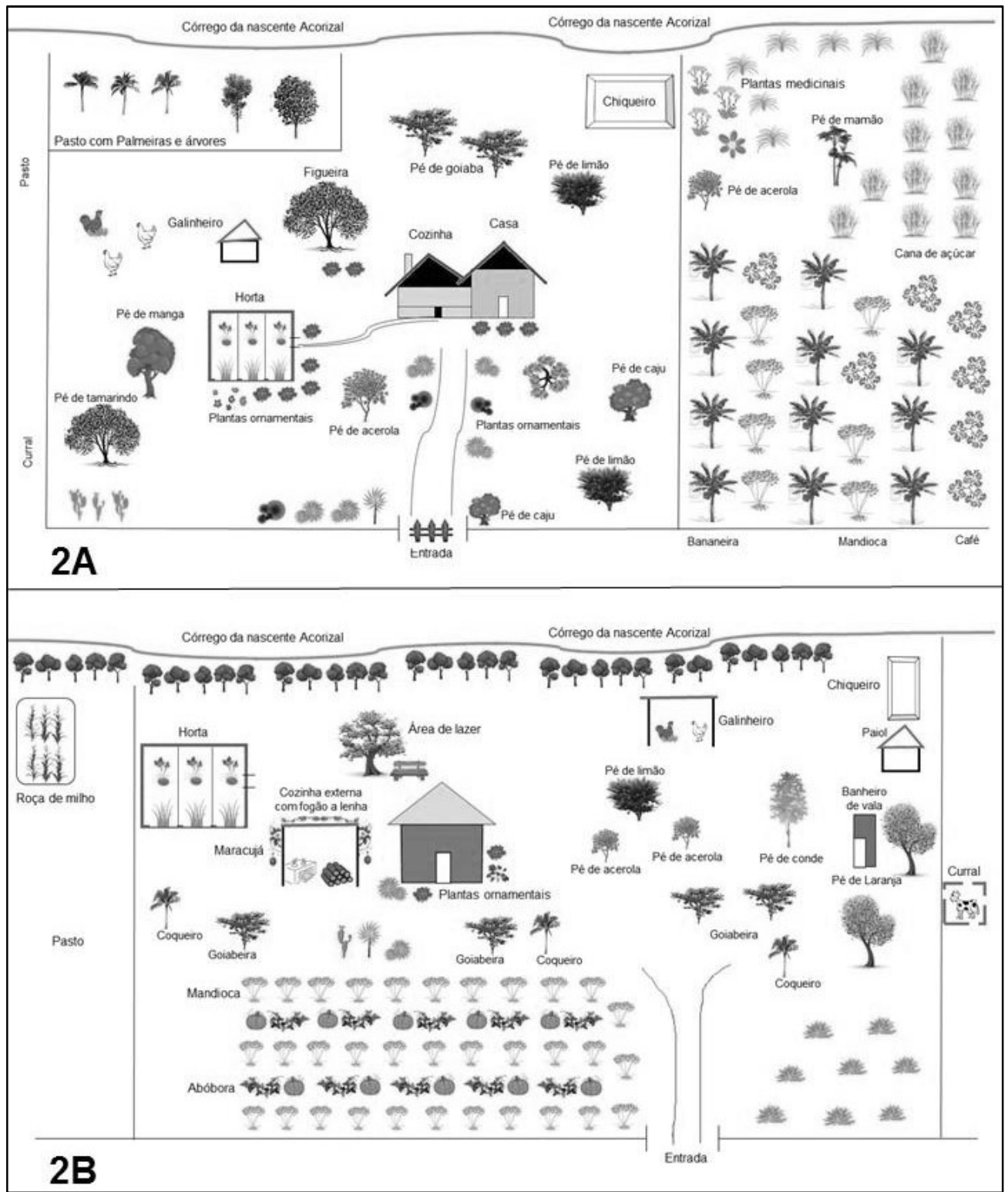

Figura 2: Croquis dos quintais de duas propriedades próximas a nascente Acorizal no Assentamento Laranjeira I, Cáceres-MT, 2013-2014. Autoria: Thaís Martins dos Santos, 2016.

$\mathrm{Na}$ figura $2 \mathrm{~A}$ está demonstrado o quintal de uma propriedade em que o agricultor dedica-se a pecuária e não tem formação de roça. No entanto, o mesmo, juntamente com sua esposa, tem um espaço no quintal delimitado por cerca ao lado direito do domićlio aonde cultivam espécies alimentares e medicinais de interesse. Neste quintal, a casa assume a posição mais comum entre as propriedades visitadas, localizando-se no centro do espaço com a ornamentação logo à frente.

Na figura 2B está apresentado o quintal cuja família cultiva espécies alimentares de uso rotineiro próximo a residência (em frente) sem a utilização de cercas para delimitação e o cultivo de plantas frutíferas para o autoconsumo. Nesta propriedade além de cultivar as espécies alimentares de uso cotidiano próximo à casa, os proprietários também destinam um espaço no pasto para a formação de roça de milho e cana-deaçúcar para autoconsumo e para a alimentação dos animais de criação (galinhas e porcos). Neste quintal, a 
casa fica situada mais ao fundo do lote e próxima ao córrego, e o espaço para o cultivo de plantas alimentares localiza-se logo à frente do domicílio. Esta estrutura organizacional do quintal não é comum às outras propriedades.

Os quintais no assentamento estudado revelam seu potencial como unidades de produção agrícola se constituindo como um importante meio de autoconsumo e geração de renda, através do cultivo de hortas, produção de frutas e criação de animais de pequeno e médio porte (MATOS, 2007), e portanto como espaços de conservação da agrobiodiversidade. Além disso, evidencia-se sua importância para a soberania alimentar das famílias desta comunidade rural, isto porque "apesar de a área destinada à produção de alimentos voltada ao autoconsumo ser relativamente pequena, ela fornece alimentos em variedade e quantidade" (MENASCHE et al., 2008, p. 150), e ainda alimentos de qualidade produzidos de forma "limpa" sem a utilização de venenos e insumos agrícolas, utilizando de práticas agroecológicas de produção aproveitando por exemplo os restos de comida para a adubação do plantio (AMOROZO, 2013).

É preciso que se entenda que os pequenos agricultores dos assentamentos, podem adotar o modelo de produção e cultivo de variedades comerciais mais produtivas e uniformes, de maior aceitação e interesse no mercado, visto que, os mesmo podem continuar a plantar as variedades locais e nativas, em áreas menores, como os quintais (AMOROZO, 2013).

\section{A roça como um espaço de tradicionalidade agrícola e experimentação}

Dentre as propriedades amostradas, $56 \%$ possuem uma área destinada exclusivamente para a formação de roça. Estas áreas estão estabelecidas em locais próximos (12 propriedades) e distantes acima de 1.000 metros (12 propriedades) das residências.

Como revelado anteriormente, muitos moradores exercem suas práticas de cultivo nos quintais, trazendo de certa forma a roça para este espaço, seja por maior comodidade por se tratar do espaço mais próximo da casa. Além disso, alguns moradores não formam roças porque arrendam o pasto para outros moradores locais para o pastoreio de gado e, outros, devido aos fatores climáticos tais como, seca e falta de água, solo rochoso, e em alguns locais do assentamento a inundação em decorrência da proximidade com a lagoa do Pantanal, que restringem tal prática.

Nas propriedades investigadas constatou-se que o preparo da terra para a formação das roças é feito tanto pelo gradeamento com trator, quanto, manual. Corroborando os dados de Oler (2012), fazem o gradeamento com maquinário aqueles proprietários que possuem renda excedente para o pagamento do serviço. No assentamento três moradores possuem trator e prestam este tipo de serviço para as outras propriedades. A associação dos assentados não possui um trator de uso comum a todos.

Quanto ao sistema de manejo adotado nas roças, é muito comum encontrar o sistema de consórcio de culturas ou policultivo, principalmente nas roças de área reduzida. Conforme a Embrapa este tipo de sistema compreende a ocupação da mesma área agrícola por duas ou mais culturas em um mesmo período, sendo este mais comum em áreas de agricultura familiar (HIRAKURI et al., 2012). 
Em 17\% das propriedades constatou-se a formação de roças sob a utilização do sistema de cultivo de apenas uma cultura agrícola e em rotação de culturas (HIRAKURI et al., 2012). Em muitas propriedades é comum encontrar roças com apenas o cultivo de uma espécie, como a cana de açúcar utilizada como ração do gado leiteiro e de corte. Para isto, alguns produtores possuem triturador de cana a motor elétrico. Estes equipamentos, assim como o uso de trator, caracterizam a mecanização da produção agrícola dentro das pequenas propriedades.

No sistema de consórcio, utilizado nas roças visitadas, constatou-se a predominância do cultivo de milho, mandioca e banana. Entre as fileiras dessas espécies agrícolas são cultivados mais comumente, o feijão (catador e de corda), a abóbora, a melancia, o café e o maxixe.

Em relação ao cultivo das variedades de banana (Musa paradisiaca L.) e mandioca (Manihot esculenta Crantz.), observou-se que em praticamente todas as roças visitadas os agricultores plantam cada variedade em covas separadas, exceto em uma roça aonde constatou-se que o agricultor cultiva variedades distintas próximas umas às outras na mesma fileira. Em visita a esta roça de mandioca, juntamente com o agricultor, perguntou-se sobre uma variedade de mandioca com o talo roxo, presente na roça, e o agricultor a denominou como "intrusa". Ao se perguntar sobre esta variedade, o mesmo disse não saber que a tinha em sua roça. Diante da constatação da variedade "intrusa", o agricultor afirmou:

"Vô dexar ela aí pra ver o que que vira, se for boa depois nós reproduz, se não, nós joga ela fora" (42, V.P.S., Assentamento Laranjeira I).

No caso da mandioca, a proximidade no cultivo de variedades distintas, propicia o surgimento de uma nova variedade da espécie devido a polinização cruzada. De acordo com Pereira et al. (1978) a mandioca possui porcentagem de polinização cruzada de 63 a 100\%, portanto a chance de cruzamento de variedades desta mesma espécie é muito alta. Diante disso, pode-se afirmar que o agricultor tem o hábito de experimentação, na qual, a planta que aparece espontaneamente na área de cultivo permanecerá somente se reproduzir algo de interesse.

No assentamento Laranjeira I, também foi identificado que a sazonalidade é um fator de importância, e ainda, fundamental para a produção agrícola. Os agricultores revelaram que existe a época do ano e o mês certo para o cultivo de algumas variedades. Os depoimentos mostram que variedades agrícolas, tais como o feijão e milho devem ser plantados na época de seca e chuva, respectivamente.

Constatou-se por meio de relatos dos moradores que não há um mês definido para o cultivo, o que eles consideram é a temporalidade local, tal como constato pelas afirmações dos moradores:

"O milho a gente pranta em novembro e o feijão em fevereiro. O feijão não aguenta com água por isso nós só pranta na seca." (43, E.M.P., Assentamento Laranjeira I).

“O milho nós pranta em janeiro e o feijão em maio." (42, C.S.F., Assentamento Laranjeira I). “O feijão mesmo nós pranta em março e abril..." (22, M.M.M., Assentamento Laranjeira I).

"[...] o milho é em novembro e o feijão assim que chovê deve sê prantado..." (68, M.J.B., Assentamento Laranjeira I).

“Nós plantamo o arroz em janeiro, porque ele gosta de água né... ai colhemo em maio... dai nós preparamo a terra né e depois que parô a chuva já plantamo o feijão [...] em maio mesmo..." (52, L.T.S., Assentamento Laranjeira I). 
Outro fator mencionado, pelos moradores, como importante para uma boa produção agrícola e revelador de marcas da manutenção de práticas agrícolas tradicionais no campo é a influência da lua no cultivo de determinadas culturas. Dentre os moradores, $32 \%$ utilizam a "força da lua" (como eles denominam tal prática) como tempo certo para o plantio, sendo maiores detentores destes conhecimentos a população mais idosa. Pilla (2006) também identificou que a população rural do Vale do Paraíba (São Paulo) faz ainda referência às fases da lua para plantar.

As práticas de manejo adotadas com orientação na lua seguem apresentadas na Tabela 1. Dentre as épocas de lua, a mais utilizada pelos moradores é a Minguante. Sobre a utilização da força da lua para o cultivo de espécies agrícolas, um dos moradores afirmou que:

"Em época de fase da lua clara não pode colher que apodrece tudo, fase de colher é da lua escura." (65, J.V.M., Assentamento Laranjeira I).

Tabela 1: Práticas de manejo adotadas com orientação na lua pelos moradores do Assentamento Laranjeira I, 20132014. Fonte: Dados coletados em campo (2014).

\begin{tabular}{c|l}
\hline Lua & \multicolumn{1}{c}{ Práticas de manejo } \\
\hline Cheia & Época em que se obtêm melhores condições de plantio. Ex: Alho \\
\hline Crescente & Época em que se obtêm melhores condições de plantio. \\
\hline Minguante & Época ideal para o cultivo de plantas tuberosas e oleaginosas. Impede que a planta "carunche". Ex: \\
Mandioca, milho, amendoim, feijão. \\
\hline Nova & Época propicia para o cultivo de arroz e de verduras. \\
\hline
\end{tabular}

Foram identificados alguns aspectos que diferenciam a agricultura utilizada por moradores nativos dos migrantes que se estabeleceram na região. Os moradores nativos desenvolvem a agricultura visando principalmente o autoconsumo das famílias, e a produção agrícola é resultado do trabalho conjunto de toda a família, extrapolando a divisão de trabalho para além das cercas que dividem as propriedades formando em alguns casos roças comunitárias. Desta forma os alimentos produzidos são divididos por toda família e quando são comercializados divide-se também a renda.

Os migrantes priorizam a comercialização do que é produzido na propriedade, tanto no que tange a produção agrícola quanto a pecuária leiteira. Não foi observada forte ligação familiar na produção agrícola dos moradores migrantes, tal como registrou-se para os produtores nativos.

Diante do contexto descrito, é evidente no assentamento Laranjeira I que a organização das famílias para a formação de roças familiares visando a produção agrícola revela a necessidade de se produzir para sobreviver isto porque produzem para a própria despesa e para a obtenção de uma fonte de renda extra. Esta forma de trabalho coletivo voltada a produção nas roças, também pode ser uma forma que os mesmos encontraram para produzir com maior eficiência e menor custo, visto que há um número maior de pessoas de apoio no trabalho destinado à produção.

Esta constatação corrobora o afirmado por Amorozo (2013), de que a conservação da agrobiodiversidade pelos pequenos agricultores está diretamente associada e dependente das motivações que alimentam o mesmo, incluindo razões de sobrevivência, questões culturais ou maximização de rendimentos financeiros. 
Constata-se, portanto, diante da observação das formas de manejo agrícola utilizadas pelos moradores do assentamento Laranjeira I, que a organização e dinâmica interna das famílias permite evidenciar que, entre esses agricultores, os cultivos e criações que empregam intensivamente as ditas tecnologias modernas coexistem, lado a lado, com técnicas tradicionais e uma expressiva produção de alimentos voltada ao autoconsumo das famílias, associada à garantia de sua segurança alimentar e, então, às suas estratégias de reprodução social (MENASCHE et al., 2008).

\section{CONCLUSÕES}

A população do Assentamento Laranjeira I é composta em sua maioria por migrantes originários de outros Estados do país, o que evidencia a diversidade cultural existente neste espaço e proporciona a troca de conhecimento sobre as diversas atividades implementadas.

Algumas famílias deixaram de produzir na roça e passaram a cultivar plantas alimentares no próprio quintal, visto que não produzem em grande escala, visam principalmente a produção para o autoconsumo. As mulheres e os filhos são os principais responsáveis pela manutenção e produção agrícola desse espaço, bem como a criação de animais de pequeno porte. Esta afirmação evidencia a importância do quintal como espaço de manutenção das espécies agrícolas alimentares essenciais para o autoconsumo das famílias e manutenção da segurança alimentar, e consequentemente colaborando para a conservação da agrobiodiversidade.

Quanto ao sistema de manejo adotado nas roças, é muito comum encontrar o sistema de consórcio de culturas ou policultivo, principalmente porque os espaços destinados ao cultivo são pequenos e o sistema de consorciação possibilita otimização da produção. O cultivo das roças é realizado, em geral, de forma coletiva pelo trabalho de todos os integrantes das famílias, desde as crianças até os mais velhos. Isso remete à uma prática agrícola utilizada principalmente pelos agricultores tradicionais.

Minoria dos moradores utilizam o sistema de cultivo com apenas uma espécie, geralmente de cana de açúcar que tem sua produção destinada à alimentação da criação de bovinos, e mandioca que atende a produção farinheira para a comercialização, bem como para o consumo das próprias famílias que a produz.

Constatou-se que principalmente a população nativa de Mato Grosso possui o hábito de formar roças comunitárias entre indivíduos de uma mesma família mas que habitam em lotes diferentes fazendo a divisão ou compartilhamento da produção para o autoconsumo das famílias, e quando realiza-se a venda dividem os lucros obtidos, utilizando de formas de manejo tradicionais. Contrária a essa realidade dos camponeses nativos, os moradores de origem migrante preferem a atividade leiteira à atividade agrícola.

Verificou-se que este assentamento é marcado por relações familiares distintas, que mesmo formadas por moradores migrantes de culturas diferenciadas apresentam marcas remanescentes de tradição agrícola. Esta população possui forte identidade cultural com a vida camponesa, e mesmo que as condições de produção comercial não tenham sido favoráveis não abandona o lote, fruto de suas lutas em movimentos sociais. A terra representa a história de vida desses moradores, garantindo a manutenção das necessidades 
básicas das famílias assentadas e de organização do local em busca de melhoria da infraestrutura do assentamento.

\section{AGRADECIMENTOS}

Ao Programa de Pós-Graduação Stricto Sensu em Ciências Ambientais da UNEMAT; à CAPES, pela concessão da bolsa de mestrado; ao Ministério do Meio Ambiente pelo financiamento do projeto de pesquisa “Recuperação das nascentes e fragmentos de mata ciliar do córrego do Assentamento Laranjeira I e mobilização para conservação dos recursos hídricos no Pantanal Matogrossense"; aos moradores do Assentamento Laranjeira I pela confiança, hospitalidade e amizade dedicados durante a trajetória desta pesquisa.

\section{REFERÊNCIAS}

ALBUQUERQUE, U. P.; LUCENA, R. F. P.. Métodos e técnicas na pesquisa etnobotânica. 1 ed. Recife: Livro Rápido/NUPEEA, 2004.

ALEXIADES, M. N.; SHELDON, J. W.. Selected guidelines for ethnobotanical research: a field manual. New York Botanical Garden, 1996.

ALMEIDA, P.; CORDEIRO, A.. Semente da paixão: estratégia comunitária de conservação de variedades locais no semiárido. Rio de Janeiro, AS-PTA, 2002.

ALTIERI M.. A falência de um modelo: sistema alimentar na era pós-petroleira. Agência Carta Maior, 2008.

AMOROZO, M. C. M.. Os quintais: funções, Importância e Futuro. In: CARNIELLO, M. A.; GUARIM NETO, G.. Quintais Mato-Grossenses: espaços de conservação e reprodução de saberes. Cáceres: EdUNEMAT, 2008. p.15-26

AMOROZO, M. C. M.. Sistemas agrícolas de pequena escala e a manutenção da agrobiodiversidade: uma revisão e contribuições. Botucatu: FCA/UNESP, 2013.

AMOROZO, M. C. M.; VIERTLER, R. B.; ALBUQUERQUE, U. P.; LUCENA, R. F. P.; CUNHA, L. V. F. C. A.. Abordagem qualitativa na coleta e análise de dados etnobotânicos. In: ALBUQUERQUE, U. P.; LUCENA, R. F. P.. Métodos e técnicas na pesquisa etnobotânica. v. 2. Recife: Livro Rápido/NUPEEA, 2008. p.73-91

BERNARD, H. R.. Research methods in cultural anthropology. United States of America: Sage Publications, 1988.

BRASIL. Instituto Nacional de Colonização e Reforma Agrária. Assentamentos. Brasília: INCRA, 2014.

BRASIL. Instituto Nacional de Colonização e Reforma Agrária. Painel de assentamentos. Mato Grosso. 2004.

BRITO, M. A.; COELHO, M. F.. Os quintais agroflorestais em regiões tropicais: unidades auto-sustentáveis. Agricultura Tropical, Cuiabá, v.4, n.1, p.7-35, 2000.
CAMPOS, C. S. S.. Campesinato autônomo: uma nova tendência gestada pelos movimentos sociais do campo. Lutas \& Resistências, v.1, p.146-162, 2006.

CASTRILLON, S. K. I.. Recuperação das nascentes e fragmentos de mata ciliar do córrego do Assentamento Laranjeira I e mobilização para conservação dos recursos hídricos no Pantanal Matogrossense. Cáceres, 2012.

CUNHA, J. M. P.; ALMEIDA, G. M. R.; RAQUEL, F.. Migração e transformações produtivas na fronteira: o caso do Mato Grosso. In: ENCONTRO DA ASSOCIAÇÃO BRASILEIRA DE ESTUDOS POPULACIONAIS, 13. Anais. Belo Horizonte: ABEP, 2002.

GEERTZ, C.. O saber local: novos ensaios em antropologia interpretativa. 3 ed. Petrópolis: Vozes, 2000.

HIRAKURI, M. H.; DEBIASI, H.; DE OLIVEIRA PROCÓPIO, S.; FRANCHINI, J. C.; DE CASTRO, C.. Sistemas de Produção: conceitos e definições no contexto agrícola. v. 14. Londrina: Embrapa Soja, 2012.

KREITLOW, J. P.; NEVES, S. M. A. S.; NEVES, R. J.; SILVA, J. S. V.; NESPOLI, A.. Análise do uso da terra no assentamento Laranjeira 1 em Cáceres-MT: subsídios para a conservação água. Cadernos de Agroecologia, Recife, v.8, n.2, 2013.

KUMAR, B. M.; NAIR, P. K. P.. The enigma of tropical homengardens. Agroflorestry Systems, v.61, p.135-152, 2004.

LUDKE, M.; ANDRÉ, M. E. D. A.. Pesquisa em Educação: Abordagens qualitativas. São Paulo: Pedagógica e Universitária, 1986.

MALUF, R.; MENEZES, F.; MARQUES, S. B.. Caderno Segurança Alimentar. Paris: FHP, 2000.

MARQUES, P. E. M.. Embates em torno da segurança e soberania alimentar: estudo de perspectivas concorrentes. Segurança Alimentar e Nutricional, Campinas, v.17, n.2, p.78-87, 2010. 
MATOS, G. R.. Sistema de produção de agricultores familiares fruticultores de Itapuranga-GO. Dissertação (Mestrado) - Universidade Federal de Goiás, Goiânia, 2007.

MENASCHE, R.; MARQUES, F. C.; ZANETTI, C.. Autoconsumo e segurança alimentar: a agricultura familiar a partir dos saberes e práticas da alimentação. Rev. Nutrição, Campinas, v.21, p.145-158, 2008.

OLER, J. R. L.. Conservação da agrobiodiversidade por agricultores de pequena escala em Mato Grosso-Brasil. Dissertação (Mestrado em Ciências Biológicas) Universidade Estadual Paulista, Rio Claro, 2012

PADOCH, C.; JONG, W.. Santa Rosa: theimpact of theforestproducts trade onanAmazonianplace and population. Advances in Economic Botany, v.6, p.214-224, 1990.

PEDROGA, J. A.; CARNIELLO, M. A.. Quintais na Fronteira Brasil-Bolívia, Comunidade de Clarinópolis. In: CARNIELLO, M.A.; GUARIM NETO, G.. Quintais Mato-Grossenses: espaços de conservação e reprodução de saberes. Cáceres: Editora UNEMAT, 2008. p.45-62

PEREIRA, A. S.; LORENZI, J. O.; NORMANHA, E. S.; SILVA, J. R.. Taxa de fecundação cruzada no cultivar de mandioca Brancade-Santa-Catarina. Bragantia, v.37, 1978.

PORTO-GONÇALVES, C. W. P.. A nova questão agrária e a reinvenção do campesinato: o caso do MST. OSAL:

Observatorio Social de América Latina, Buenos Aires, v.6, n.16, 2005.
ROSSET, P.. Soberania Alimentaria: reclamo mundial del Movimento Campesino. 2004.

SILVA, T. P.; ALMEIDA, R. A.; KUDLAVICZ, M.. Os assentamentos rurais em Cáceres/MT: espaço de vida e luta camponesa. Revista Eletrônica da Associação dos Geógrafos Brasileiros, Três Lagoas, n.15, 2012.

TSUKAMOTO, R. Y.; ASARI, A. Y.. Assentamentos rurais e agricultura familiar: processo de territorialização e perspectivas de auto-sustentação. Geografia, Londrina, v.12, n.1, p.483-494, 2003.

VIA CAMPESINA DO BRASIL. Histórico, natureza e linhas políticas internacionais: Cartilha da Via Campesina. São Paulo, 2002.

VIERTLER, R. B.. Métodos antropológicos como ferramenta para estudos em etnobiologia e etnoecologia. In: AMOROZO, M. C. M.; MING, L. C.; SILVA, S. P.. Métodos de coleta e análise de dados em etnobiologia, etnoecologia e disciplinas correlatas. Rio Claro: UNESP, 2002.

WANDERLEY, M. N. B.. A valorização da agricultura familiar e a reivindicação da ruralidade no Brasil. Desenvolvimento e Meio Ambiente, v. 2, 2000.

WILLIAMS, J. T.. Identificação e proteção das origens de nossas plantas. In: WILSON, E. O.. Biodiversidade. Rio de Janeiro: Nova Fronteira, 1997. p.303-12

WITTMAN, H.; DESMARAIS, A. A.; WIEBE, N.. Food sovereignty: Reconnecting food, nature and community. Oakland: Food First. 2010 